\title{
Effect of Cr on the Mineral Structure and Composition of Cement Clinker and Its Solidification Behavior
}

\author{
Haihong Fan *, Mengqi Lv, Xiaosha Wang, Jianmin Xiao, Xiaofan Mi and Luwei Jia \\ College of Materials Science and Engineering, Xi'an University of Architecture and Technology, Xi'an 710055, \\ China; lvmeng_qi@163.com (M.L.); xiaosha0309@126.com (X.W.); xiaomin0622@126.com (J.X.); \\ mxf0912@126.com (X.M.); jlw0925@126.com (L.J.) \\ * Correspondence: fanhaihongfu@sina.com
}

Received: 8 March 2020; Accepted: 24 March 2020; Published: 26 March 2020

\begin{abstract}
In order to reveal the solidification behavior of $\mathrm{Cr}$ in the cement clinker mineral phase, ${ }^{29} \mathrm{Si}$ magic-angle spinning nuclear magnetic resonance, $\mathrm{X}$-ray diffraction, and scanning electron microscopy with energy-dispersive $\mathrm{X}$-ray spectroscopy techniques were used to analyze the morphology and composition of the cement clinker mineral phase doped with $\mathrm{Cr}$. The results showed that the addition of $\mathrm{Cr}$ did not change the chemical environment of ${ }^{29} \mathrm{Si}$ in the clinker mineral phase, and it was still an isolated silicon-oxygen tetrahedron. Cr affected the orientation of the silicon-oxygen tetrahedron and the coordination number of calcium, leading to the formation of defects in the crystal structure of the clinker mineral phase, by replacing $\mathrm{Ca}^{2+}$ into the mineral phase lattice to form a new mineral phase $\mathrm{Ca}_{3} \mathrm{Cr}_{2}\left(\mathrm{SiO}_{4}\right)_{3}$. Cr acted as a stabilizer for the formation of $\beta-\mathrm{C}_{2} \mathrm{~S}$ in the clinker calcination. As the amount of $\mathrm{Cr}$ increased, the relative content of $\mathrm{C}_{3} \mathrm{~S}$ decreased and the relative content of $\mathrm{C}_{2} \mathrm{~S}$ increased. Further, $\mathrm{Cr}$ easily dissolved in $\mathrm{C}_{2} \mathrm{~S}$, while it was not found in $\mathrm{C}_{3} \mathrm{~S}$. This study is conducive to further research on the mechanism of heavy metal solidification in cement clinker. Furthermore, it is important to evaluate the environmental risk of heavy metals in the process of sludge disposal through cement kiln and promote the utilization of sludge resources and the sustainable development of the cement industry.
\end{abstract}

Keywords: clinker; heavy metal; solidification; ${ }^{29} \mathrm{Si}$ MAS NMR; Cr

\section{Introduction}

As of the end of June 2018, the amount of municipal and industrial sludge in China reached 90 million tons, with a utilization rate of only $30 \%$, and random landfills have seriously polluted the environment. The main reason for restricting its recycling is that it contains heavy metals. The refractory and enrichment of heavy metals hinders the sludge resource utilization. At present, the coprocessing technology of cement kilns is recognized as one of the safest and most effective sludge disposal methods in the world. By utilizing its advantages such as high temperature in the kiln, long residence time of materials, and stable incineration status, dangerous substances such as heavy metal ions in the sludge can be solidified in the mineral phase of cement clinker [1-3]. Heavy metal ions will form an enriched phase due to the crystal structure defect of the cement clinker mineral phase itself, and will also be present in the empty interstitial spaces of the mineral phase [4-8]. Therefore, the research on the influence of heavy metal ions on the calcination degree of clinker and the mineral phase structure of clinker has gained attention.

Chromium is one of the heavy metal elements often present in sludge. The influence of chromium on clinker quality must be considered in the safe and environmentally friendly production of chromium-containing sludge in the coprocessing of cement kilns. Scientists all around the world have carried out significant research on this. Katyal [9] found that when the content of $\mathrm{Cr}_{2} \mathrm{O}_{3}$ is less than $2 \%$, 
T-type $\mathrm{C}_{3} \mathrm{~S}$ is formed. When the $\mathrm{Cr}_{2} \mathrm{O}_{3}$ content increased to $4-5 \%$, the $\mathrm{C}_{3} \mathrm{~S}$ crystal form changes to the $\mathrm{M} 1$ form, leading to the growth of a new mineral phase $\mathrm{CaCrO}_{4}$. However, according to Enculescu [10], when the content of $\mathrm{Cr}_{2} \mathrm{O}_{3}$ is $0.5 \%-2.0 \%$, the crystal form of $\mathrm{C}_{3} \mathrm{~S}$ changes to the M1 type. At the same time, when the content of $\mathrm{Cr}_{2} \mathrm{O}_{3}$ is $4 \%$, a new phase, $\mathrm{CaCrO}_{4}$, is also formed. $\mathrm{Xi}$ and Kolovo [11-13] found that $\mathrm{Cr}$ does not exist alone in the form of compounds during the clinker calcination. It exists mainly in the form of $\mathrm{Cr}^{3+}$ and $\mathrm{Cr}^{5+}$ which replace $\mathrm{Si}^{4+}$ in silicate minerals. Barros [14] showed that the incorporation of $\mathrm{Cr}$ in the clinker can inhibit the formation of $C_{2} S$, while Fierens [15] believed that doping $\mathrm{Cr}$ can prevent the formation of $\mathrm{C}_{3} \mathrm{~S}$ in the clinker. Stephan $[16,17]$ pointed out that when $\mathrm{Cr}$ is added at a low concentration $(0.02 \%-0.5 \%)$, it has no effect on the formation of $C_{3} S$. Only at a high content (greater than $1.0 \%$ ), $\mathrm{Cr}$ will decompose $\mathrm{C}_{3} \mathrm{~S}$ to generate more $\mathrm{C}_{2} \mathrm{~S}$ and $\mathrm{CaO}$. Thus, previous studies on the crystal structure change, generation quality of clinker mineral phases doped with $\mathrm{Cr}$, and role of $\mathrm{Cr}$ in the reduction of the stability of $\mathrm{C}_{3} \mathrm{~S}$ or $\mathrm{C}_{2} \mathrm{~S}$ are not consistent [18].

In this study, chromium nitrate nonahydrate was used for doping cement clinker. Techniques such as ${ }^{29}$ Si magic-angle spinning nuclear magnetic resonance (MAS NMR), X-ray diffraction (XRD), and scanning electron microscopy with energy-dispersive X-ray spectroscopy (SEM-EDS) were used to analyze the cement clinker doped with $\mathrm{Cr}$ from the point of view of mineral phase structure, content, and mineral phase formation and morphology. The solidification behavior of $\mathrm{Cr}$ in the mineral phase of cement clinker and the degree of its influence on the formation of the mineral phase were investigated. The aim is to provide a new theoretical basis for the high efficiency and safety of solid waste disposal in cement kilns.

\section{Materials and Methods}

\subsection{Raw Materials}

The raw materials used in the present study were limestone, clay, and copper slag from a cement plant in Xianyang, Shaanxi. The chemical composition of each raw material is shown in Table 1. The heavy metal reagent used was chromium nitrate nonahydrate $\left(\mathrm{Cr}\left(\mathrm{NO}_{3}\right)_{3} \cdot 9 \mathrm{H}_{2} \mathrm{O}\right)$ (analytical grade; Sinopharm Chemical Reagent Co., Ltd, Tianjin, China).

Table 1. Chemical composition of the raw materials (wt \%).

\begin{tabular}{ccccc}
\hline Composition & $\mathbf{C a O}$ & $\mathbf{S i O}_{\mathbf{2}}$ & $\mathbf{A l}_{\mathbf{2}} \mathbf{O}_{\mathbf{3}}$ & $\mathrm{Fe}_{\mathbf{2}} \mathbf{O}_{\mathbf{3}}$ \\
\hline Limestone & 56.80 & 0.28 & 0.12 & 0.05 \\
Clay & 14.52 & 48.25 & 10.28 & 4.60 \\
Copper slag & 6.55 & 30.17 & 8.93 & 48.04 \\
\hline
\end{tabular}

\subsection{Sample Preparation}

Blank samples were prepared according to the three major cement clinker ratio values $\mathrm{IM}=1.309$, $\mathrm{SM}=2.580$, and $\mathrm{KH}=0.893$. Based on this, the total amount of $\mathrm{Cr}$ was $0.4 \%, 0.6 \%, 0.8 \%, 1.0 \%$, and $5.0 \%$ (with respect to pure heavy metal elements). For example, when the total amount of $\mathrm{Cr}$ was $0.4 \%, 3.1 \%$ of chromium nitrate nonahydrate $\left(\mathrm{Cr}\left(\mathrm{NO}_{3}\right)_{3} \cdot 9 \mathrm{H}_{2} \mathrm{O}\right)$ was used. The ratio of raw materials is shown in Table 2. Appropriate amounts of the raw materials were mixed uniformly. The mixture along with an appropriate amount of distilled water was added in the pressure forming machine (Wanbo Instrument Co., Ltd, Hebi, China) to make a small test specimen of diameter $13 \mathrm{~mm} \times 13 \mathrm{~mm}$. The specimens were dried in an oven (Kewei Yongxing Instrument Co., Ltd, Beijing, China) at $105^{\circ} \mathrm{C}$. After drying, the test specimens were prefired in a muffle furnace (Capulet Limited, Britain) at $950{ }^{\circ} \mathrm{C}$ for $30 \mathrm{~min}$, and then placed in a high-temperature furnace at $1450{ }^{\circ} \mathrm{C}$ for $30 \mathrm{~min}$. The test specimens were then taken out and naturally cooled in air to obtain clinker samples. 
Table 2. Raw material ratio/wt \%.

\begin{tabular}{ccccccc}
\hline Raw Material & C0 & C0.4 & C0.6 & C0.8 & C1.0 & C5.0 \\
\hline Cr & 0 & 0.4 & 0.6 & 0.8 & 1.0 & 5.0 \\
Limestone & 68.73 & 68.73 & 68.73 & 68.73 & 68.73 & 68.73 \\
Clay & 28.92 & 28.92 & 28.92 & 28.92 & 28.92 & 28.92 \\
Copper slag & 2.35 & 2.35 & 2.35 & 2.35 & 2.35 & 2.35 \\
\hline
\end{tabular}

\subsection{Characterization and Analysis}

Using the AVANCE 400 (SB) full digital NMR spectrometer of Bruker BioSpin Co., Ltd. in Switzerland the MAS-NMR analysis of ${ }^{29} \mathrm{Si}$ (Bruker Biospin Co., Ltd, Switzerland) was used to analyze the clinker mineral phase structure. ${ }^{29} \mathrm{Si}$ resonance frequency used was $79.49 \mathrm{~Hz}$. Peak fitting software was employed to analyze the mineral phase content. The composition of the clinker mineral phase was investigated by XRD using the Japan Rigaku D/Max 2200 (Japan Rigaku Co., Ltd, Japan), where target was copper, and $\mathrm{K} \alpha$ rays with $\lambda=0.15418 \mathrm{~nm}$ were used. The morphology of clinker mineral phase was studied by SEM using the FEI Quanta 200 (FEI Limited, the U S), and EDS (FEI Limited, the U S) was used to analyze the distribution of $\mathrm{Cr}$ in clinker mineral phase.

\section{Results}

\subsection{Effect of $\mathrm{Cr}$ on the Structure and Content of Mineral Phase}

The solid nuclear magnetic resonance technology is useful for obtaining information about the structure of the material by analyzing the NMR spectra. Information regarding the number, position, width, and area of spectral lines can be inferred from the signal obtained by the NMR spectrum diagram. The number and position of spectral lines are reflected by the chemical shift; the changes in chemical shift indicate the changes in the chemical environment in which the nucleus is located, namely, the molecular structure of the material $[19,20]$. In the ${ }^{29} \mathrm{Si} \mathrm{MAS} \mathrm{NMR} \mathrm{study,} \mathrm{the} \mathrm{chemical}$ environment of ${ }^{29} \mathrm{Si}$ is represented by $\mathrm{Q}^{\mathrm{n}}$, where $\mathrm{n}(0-4)$ is the number of oxygen atoms shared by each silicon-oxygen tetrahedron and the adjacent silicon-oxygen tetrahedral. While $\mathrm{Q}^{0}$ represents an island-shaped $\left[\mathrm{SiO}_{4}\right]$ tetrahedron with a chemical shift in the range of -68 to $-79 \mathrm{ppm}, \mathrm{Q}^{1}$ represents the silicon-oxygen tetrahedron connected with one silicon-oxygen tetrahedron, that is, the silicon-oxygen tetrahedron is at the end of the straight chain in the dimer or hypermer, and the chemical shift is in the range of -76 -82 ppm. Further, $\mathrm{Q}^{2}$ represents the silicon-oxygen tetrahedron connected with two silicon-oxygen tetrahedrons, that is, the silicon-oxygen tetrahedron is in the middle of the straight chain or in the ring structure, and the chemical shift is in the range of $-82 \sim-88 \mathrm{ppm}$. Similarly, $\mathrm{Q}^{3}$ indicates the silicon-oxygen tetrahedron connected with three silicon-oxygen tetrahedrons, which has the branch of chain, double-chain polymerization structure, or layered structure with a chemical shift in the range of $-88 \sim-98$ ppm. Finally, $\mathrm{Q}^{4}$ depicts four silicon-oxygen tetrahedrons forming a three-dimensional network structure with a chemical shift in the range of $-98 \sim-129 \mathrm{ppm}$ [19-22].

Solid-state magnetic resonance technology is used to analyze the structure of solid materials with higher crystallinity or the structure of amorphous solid materials with lower crystallinity. Its unique quantitative analysis method has been applied to the research of cement-based materials. Cement clinker is mainly composed of dicalcium silicate $\left(C_{2} S\right)$ and tricalcium silicate $\left(C_{3} S\right)$. The ${ }^{29} \mathrm{Si} \mathrm{MAS} \mathrm{NMR}$ analysis performed in the past [19-22] shows that the silicon-oxygen tetrahedrons in $C_{2} S$ and $C_{3} S$ are isolated structures, meaning that the chemical environment in which ${ }^{29} \mathrm{Si}$ is located is $\mathrm{Q}^{0}$. The ${ }^{29} \mathrm{Si}$ MAS NMR technique is, thus, suitable for analyzing the effect of $\mathrm{Cr}$ on the mineral phase structure of cement clinker.

Figure 1 is a ${ }^{29} \mathrm{Si}$ MAS NMR spectrum of cement clinker fired with $\mathrm{Cr}$. The chemical shift of the spectrum of the clinker with a Cr content of $0 \%-1 \%$ is $-71.56 \mathrm{ppm}$, and that of the clinker with a $\mathrm{Cr}$ content of $5 \%$ is $-71.17 \mathrm{ppm}$. In addition, as the Cr content varies from $0.4 \%$ to $0.8 \%$, the NMR peak increases, and the peak becomes sharper. When the $\mathrm{Cr}$ content is $0.8 \%$, the peak is at the highest 
magnitude, but it decreases at a content of $1.0 \%$. The spectrum also becomes wider. Although the chemical shift of the ${ }^{29} \mathrm{Si}$ MAS NMR spectrum has changed, the chemical environment of the ${ }^{29} \mathrm{Si}$ is still $\mathrm{Q}^{0}$. The nature of the $\mathrm{X}$ group in the Si-O-X unit will affect the chemical shift of ${ }^{29} \mathrm{Si}$. While the $\mathrm{Cr}-\mathrm{O}$ bond energy is weaker than that of Ca-O [22], the electronegativity of $\mathrm{Cr}^{3+}(1.66)$ is greater than that of $\mathrm{Ca}^{2+}(1.01)$. As a power-supplying group, $\mathrm{Cr}^{3+}$ replaces $\mathrm{Ca}^{2+}$, thus weakening the electron cloud density around ${ }^{29} \mathrm{Si}$, increasing the chemical shift, and shifting the spectral line to a low magnitude. For $\mathrm{Cr}$ content in the range of $0.4 \%-1.0 \%$, the peak of the ${ }^{29} \mathrm{Si}$ MAS NMR spectrum is relatively unchanged, smooth, and sharp. The widening phenomenon occurs when the $\mathrm{Cr}$ content reaches $5.0 \%$, indicating that the high $\mathrm{Cr}$ content causes distortion of the crystal structure of the mineral phase [21], leading to generation of new mineral phases in the clinker.

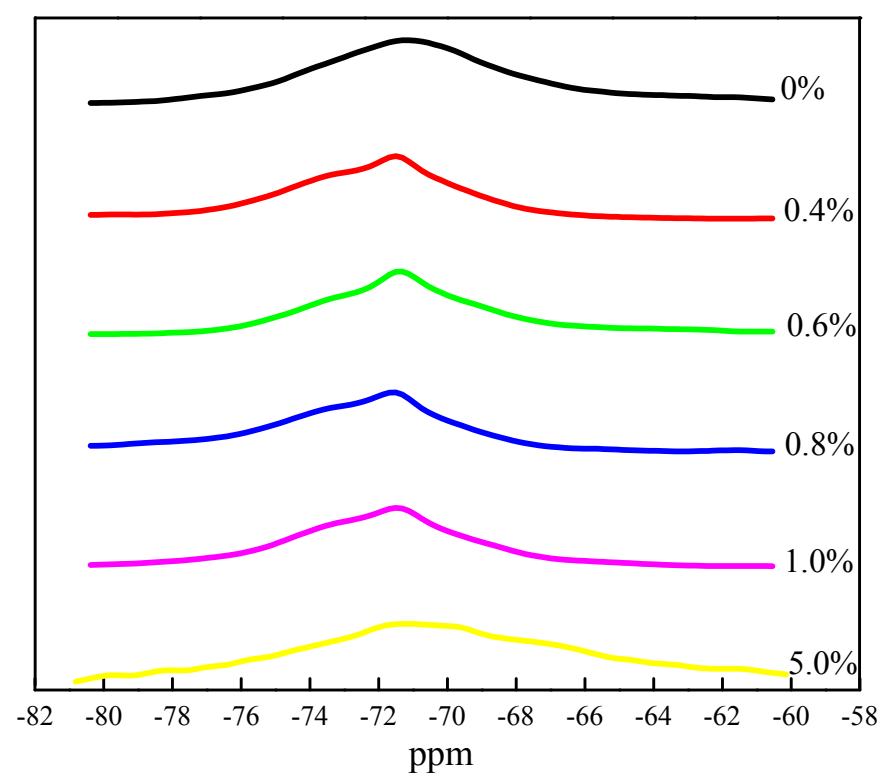

Figure 1. ${ }^{29} \mathrm{Si}$ MAS NMR spectrum of clinker with different $\mathrm{Cr}$ content.

In this ${ }^{29}$ Si MAS NMR analysis, the NMR spectrum peaks can be fitted. Different chemical shifts represent different structures in the sample. Deconvolution integration is performed to calculate the integrated area, and then the relative content of different structures can be estimated [23]. $C_{2} S$ has four crystal forms, namely, $\alpha-C_{2} S, \alpha{ }^{\prime} \mathrm{L}-\mathrm{C}_{2} \mathrm{~S}, \beta-\mathrm{C}_{2} \mathrm{~S}$, and $\gamma-\mathrm{C}_{2} \mathrm{~S}$. The chemical shifts corresponding to each crystal form are $-70.7,-70.8,-71.4$, and $-73.5 \mathrm{ppm}$. $\mathrm{C}_{3} \mathrm{~S}$ has $9 \mathrm{Si}$ sites, the chemical shifts of which correspond to 7 positions of $-69.2,-71.9,-72.9,-73.6,-73.8,-74.0$, and $-74.7 \mathrm{ppm}$, respectively [24]. Figure 2 depicts the peak fitting of the original spectrum using PeakFit software. This helped to determine the mineral phase composition represented by each peak position, and the area integral formula was used to calculate the relative content of each mineral phase. The relative percentages of $C_{3} S, \beta-C_{2} S$, a- $C_{2} S$, and $C_{2} S$, and the ratio of $C_{2} S$ to $C_{3} S$ were obtained, as shown in Table 3. With an increase in $\mathrm{Cr}$ content, the relative content of $C_{3} S$ gradually decreases, while that of $C_{2} S$ and $\beta-C_{2} S$ gradually increases. Further, the ratio of $\mathrm{C}_{2} \mathrm{~S}$ to $\mathrm{C}_{3} \mathrm{~S}$ shows an upward trend. The relative content of $\alpha-\mathrm{C}_{2} \mathrm{~S}$ reaches a maximum of $13.46 \%$ when the $\mathrm{Cr}$ content is $1.0 \%$, and then decreases. When the $\mathrm{Cr}$ content is $5.0 \%$, the relative content of $C_{3} S$ in the clinker reaches $32.56 \%$, while that of $C_{2} S$ and $\beta-C_{2} S$ is $27.44 \%$ and $37.44 \%$, respectively. The ratio of $\mathrm{C}_{2} \mathrm{~S}$ to $\mathrm{C}_{3} \mathrm{~S}$ is 0.6 , probably due to the introduction of heavy metal $\mathrm{Cr}$. Studies have shown that some heavy metal elements $(\mathrm{Cr}, \mathrm{Pb}, \mathrm{Cd}, \mathrm{Zn}$, etc.) act as stabilizers in the clinker calcination. They reduce the decomposition temperature of $\mathrm{CaCO}_{3}$ and the formation temperature of $C_{2} S$, thus stabilizing $\beta-C_{2} S$, and then consequently $C_{2} S$, leading to an increase in $\mathrm{C}_{2} \mathrm{~S}$ content [25]. In this study, since the addition of $\mathrm{Cr}$ has a positive effect on the cell size and the stability of the crystal form of $\beta-C_{2} S$, the $C_{2} S$ content was seen to increase accordingly. The greater the amount of $\mathrm{Cr}$, the more obvious was the effect on $\mathrm{C}_{2} \mathrm{~S}$. 

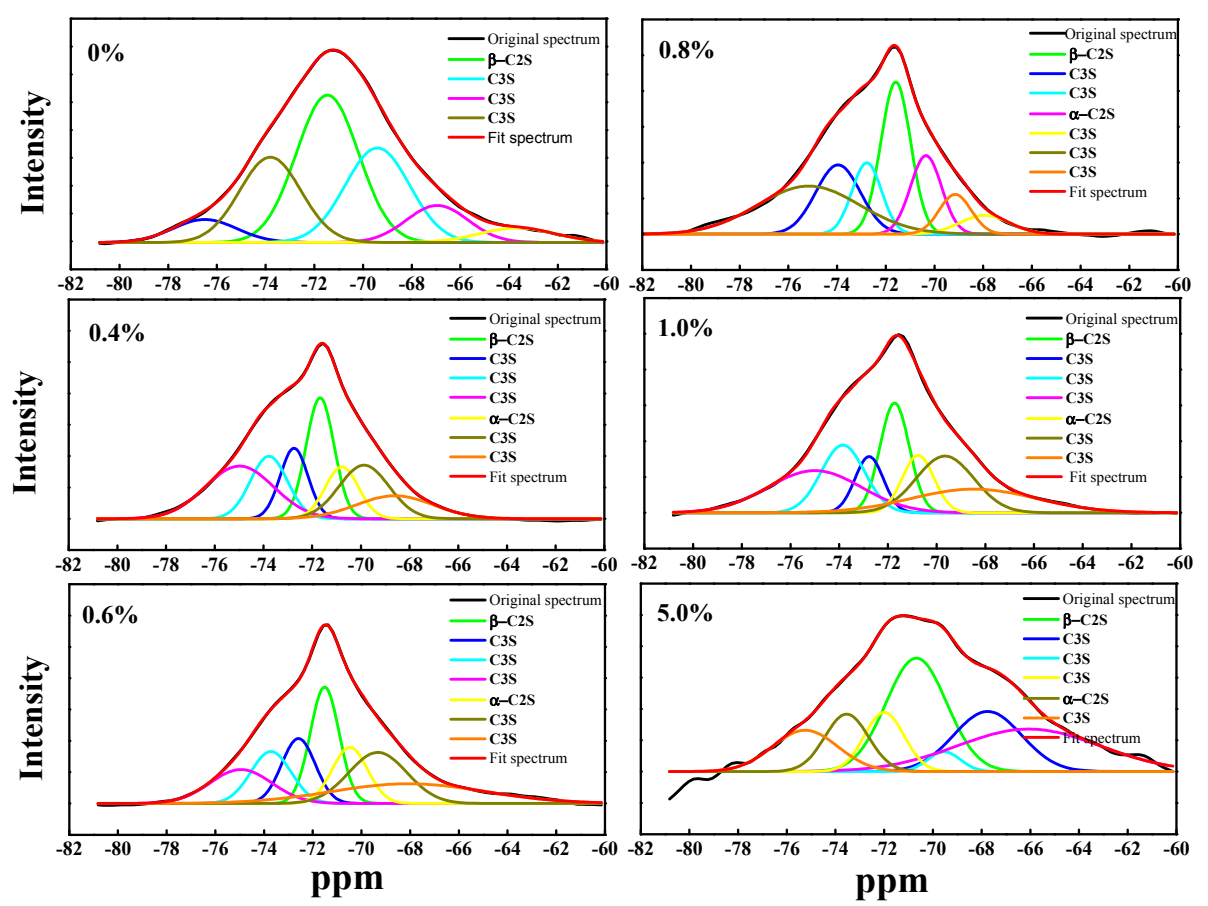

Figure 2. ${ }^{29}$ Si MAS NMR spectrum after fitting peaks of different $\mathrm{Cr}$ doping clinker.

Table 3. Percentage of $\beta-C_{2} S, C_{2} S$, and $C_{3} S$ after peak fitting/wt $\%$.

\begin{tabular}{ccccccc}
\hline Content & $\mathbf{0 \%}$ & $\mathbf{0 . 4} \%$ & $\mathbf{0 . 6} \%$ & $\mathbf{0 . 8} \%$ & $\mathbf{1 . 0 \%}$ & $\mathbf{5 . 0 \%}$ \\
\hline$\beta-\mathrm{C}_{2} \mathrm{~S}$ & 36.2 & 19.43 & 19.03 & 23.51 & 23.12 & 27.44 \\
$\mathrm{C}_{2} \mathrm{~S}$ & 36.2 & 29.36 & 30.21 & 36.13 & 36.58 & 37.44 \\
$\mathrm{C}_{3} \mathrm{~S}$ & 63.8 & 70.64 & 70.72 & 63.87 & 63.42 & 62.56 \\
\hline
\end{tabular}

Note: Relative percentage content refers to the percentage content of each component in the total silicon substance.

\subsection{Effect of $\mathrm{Cr}$ on Mineral Phase Formation}

XRD analysis of $\mathrm{Cr}$-doped cement clinker was performed. Figure 3 shows that the main mineral phases in the $\mathrm{Cr}$-doped clinker are $\mathrm{C}_{3} \mathrm{~S}, \mathrm{C}_{2} \mathrm{~S}, \mathrm{C}_{3} \mathrm{~A}$, and $\mathrm{C}_{4} \mathrm{AF}$. Compared with the blank sample, the $\mathrm{C}_{2} \mathrm{~S}$ and $\mathrm{C}_{3} \mathrm{~S}$ diffraction peaks for the five kinds of $\mathrm{Cr}$-doped clinker are obvious. As the $\mathrm{Cr}$ amount increases, the $\mathrm{C}_{2} \mathrm{~S}$ peak intensity and the number of peaks increase, indicating that a large amount of $\mathrm{C}_{2} \mathrm{~S}$ is generated in the clinker. When the $\mathrm{Cr}$ content is $5.0 \%$, the peak strength and the amount of $\mathrm{C}_{3} \mathrm{~S}$ in the clinker decrease, indicating that $\mathrm{C}_{3} \mathrm{~S}$ is generated to a lesser extent. Comprehensively, it is shown that $\mathrm{Cr}$ doping is beneficial to the stable formation of $\mathrm{C}_{2} \mathrm{~S}$ and promotes the presence of $\mathrm{C}_{2} \mathrm{~S}$ content, while an increase in the $\mathrm{Cr}$ amount inhibits the formation of $\mathrm{C}_{3} \mathrm{~S}$. In the five kinds of clinker, the $C_{3} A$ and $C_{4} A F$ peaks are not obvious, and the peak strength is weak, indicating that the $C_{3} A$ and $\mathrm{C}_{4} \mathrm{AF}$ contents are very small. In addition, when the $\mathrm{Cr}$ content is $5.0 \%$, a weak intensity diffraction peak appears between the diffraction angles of $33^{\circ}$ and $34^{\circ}$. The mineral phase of this diffraction peak is uvarovite, $\mathrm{Ca}_{3} \mathrm{Cr}_{2}\left(\mathrm{SiO}_{4}\right)_{3}$, indicating that the addition of $\mathrm{Cr}$ affects the normal formation of crystal structure of clinker mineral phase, and then induces the formation of new crystal forms.

Figure 4 shows the analysis of the crystal structures of $\mathrm{C}_{3} \mathrm{~S}, \mathrm{C}_{2} \mathrm{~S}$, and uvarovite. $\mathrm{C}_{3} \mathrm{~S}$ crystals are tightly packed with oxygen, calcium, and silicon entering the voids as octahedron and tetrahedron. The apex angles of $\left[\mathrm{SiO}_{4}\right]$ tetrahedron are independent and exist in an isolated state. $\mathrm{C}_{2} \mathrm{~S}$ is composed of $\left[\mathrm{SiO}_{4}\right]^{4}$-tetrahedron and $\mathrm{Ca}^{2+}$. Compared with $\mathrm{C}_{3} \mathrm{~S}, \mathrm{C}_{2} \mathrm{~S}$ has less $\mathrm{O}^{2-}$ in ionic composition, making the structure of $\mathrm{C}_{2} \mathrm{~S}$ more stable. In the crystal structure of $\mathrm{Ca}_{3} \mathrm{Cr}_{2}\left(\mathrm{SiO}_{4}\right)_{3}$, trivalent $\mathrm{Cr}$ ions, $\left[\mathrm{CrO}_{6}\right]$, are formed with a coordination number of 6 , connected with the isolated $\left[\mathrm{SiO}_{4}\right]$ tetrahedron, forming some larger distorted cubic voids, and each apex angle is occupied by oxygen. Table 4 shows the 
radius, coordination number, and electronegativity of each ion. There are large differences in chemical structural parameters such as ionic radius, ligancy, and electronegativity between $\mathrm{Cr}^{3+}, \mathrm{Ca}^{2+}$, and $\mathrm{Si}^{4+}[26,27]$. The ionic radius of $\mathrm{Cr}^{3+}$ lies between those of $\mathrm{Ca}^{2+}$ and $\mathrm{Si}^{4+}$, and its electronegativity is close to that of $\mathrm{Si}^{4+}$. From the point of view of the coordination number, $\mathrm{Cr}^{3+}$ replaces $\mathrm{Ca}^{2+}$, shifting the charge center of the ionic group, and causing the orientation of the silicon-oxygen tetrahedron and the coordination number of calcium to change. This means that the addition of $\mathrm{Cr}$ changes the mode of oxygen accumulation or accumulation density, and the cell parameters, resulting in the modification of silicate crystal shape and the generation of new calcium chrome garnet crystals.

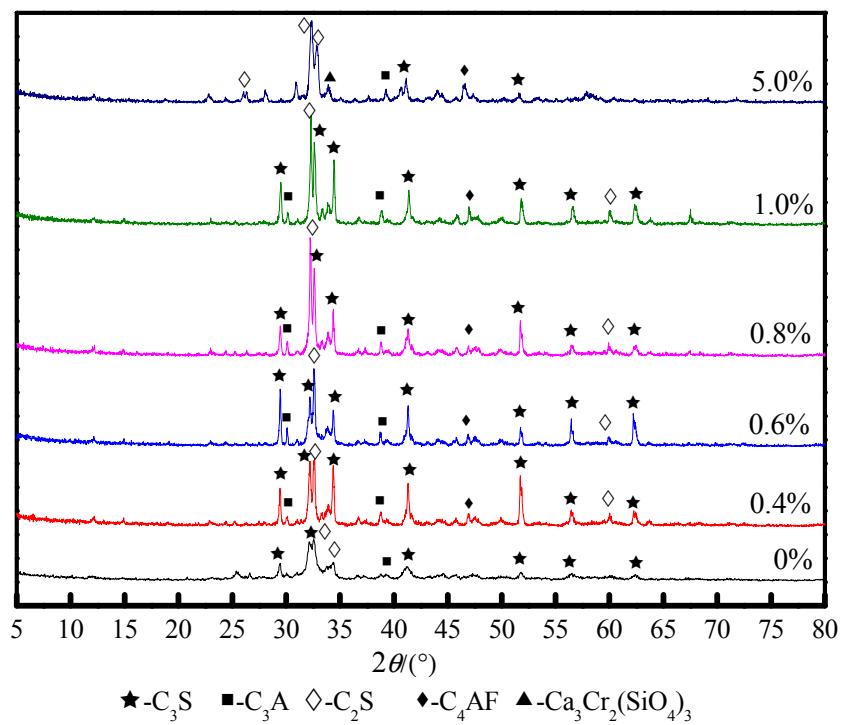

Figure 3. XRD patterns of clinker with varying $\mathrm{Cr}$ content.
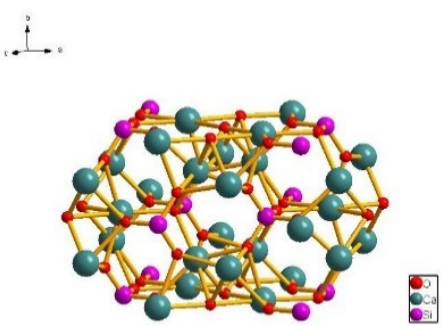
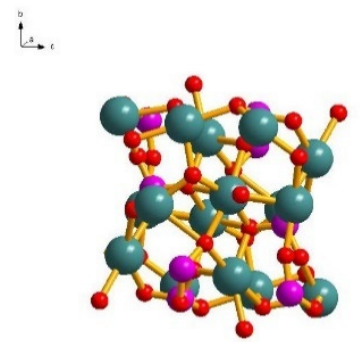

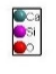

Figure 4. Crystal structure of silicate minerals.

Table 4. Ionic radius, coordination number, and electronegativity of ions.

\begin{tabular}{cccc}
\hline Ion & Ionic Radius/pm & Electronegativity & Ligancy \\
\hline $\mathrm{Ca}^{2+}$ & 100 & 1.0 & 6 \\
$\mathrm{Si}^{4+}$ & 40 & 1.9 & 4 \\
$\mathrm{Cr}^{3+}$ & 69 & 1.6 & 6 \\
\hline
\end{tabular}

\subsection{Effect of $\mathrm{Cr}$ on Morphology of the Mineral Phase}

Figure $5 \mathrm{a}-\mathrm{c}$ depict the SEM images of clinker with $0.8 \%, 1.0 \%$, and $5.0 \% \mathrm{Cr}$, respectively. The SEM backscattering technique was used for these images. Point 1 in Figure $5 \mathrm{a}$ is a round grain, and may possibly be $C_{2} S$. Point 2 is plate-like, and may be $C_{3} S$. In all the images, the $C_{3} S$ and $C_{2} S$ mineral boundaries are clear and easy to distinguish. When the $\mathrm{Cr}$ content is increased to $5.0 \%$, the $\mathrm{C}_{2} \mathrm{~S}$ generation dominates, the aggregation state is strong, the mineral phase agglomerates greatly, and the $\mathrm{C}_{3} \mathrm{~S}$ mineral phase is reduced. The high $\mathrm{Cr}$ content is beneficial to the stable formation of $\mathrm{C}_{2} \mathrm{~S}$ 
and inhibits the formation of $\mathrm{C}_{3} \mathrm{~S}$. EDS spectrum analysis was performed on some microregions in the SEM images. The results are shown in Table 5. In Figure 5b, the Ca/Si atomic ratio in the EDS-1 microregion is 2.07, which is considered to be the $\mathrm{C}_{2} \mathrm{~S}$ mineral phase, and the $\mathrm{Ca} / \mathrm{Si}$ atomic ratio in the EDS-2 microregion is 2.67, which is considered to be the $\mathrm{C}_{3} S$ mineral phase. The composition of EDS microregion and the content of $\mathrm{Cr}$ in mineral phase show that $\mathrm{Cr}$ is easily dissolved in $\mathrm{C}_{2} \mathrm{~S}$, and the content of $\mathrm{Cr}$ in $\mathrm{C}_{2} \mathrm{~S}$ increases with the increase of $\mathrm{Cr}$ content. When the $\mathrm{Cr}$ content is $5.0 \%$, its total mass in the microregion is about $3.98 \%$.
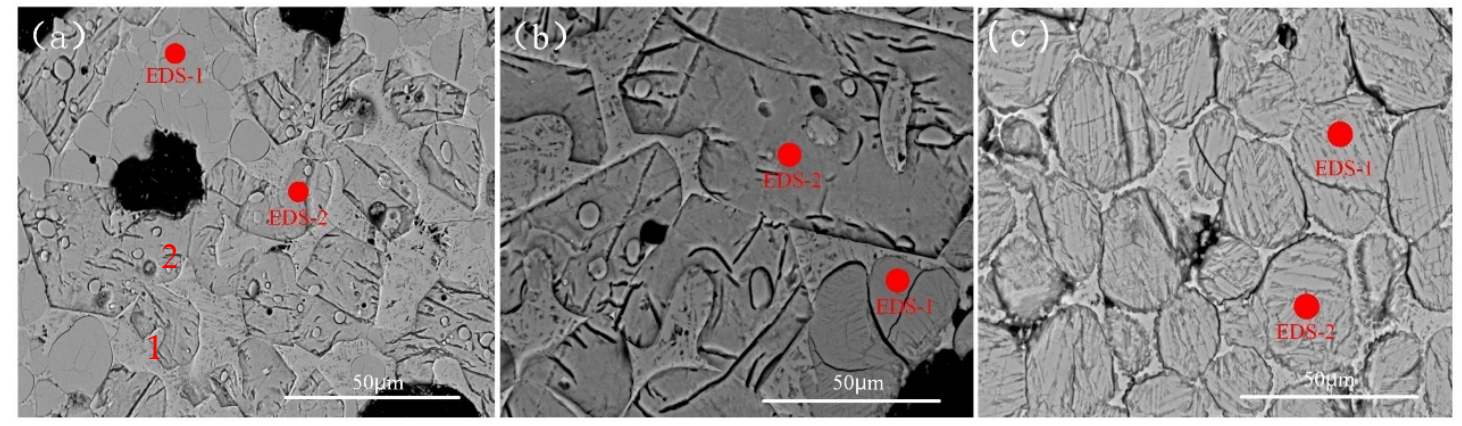

Figure 5. SEM spectrum of Cr-doped cement clinker. (a) with $0.8 \% \mathrm{Cr}$; (b) with $1.0 \% \mathrm{Cr}$; (c) with $5.0 \% \mathrm{Cr}$.

Table 5. EDS analysis of Cr-doped clinker microregion.

\begin{tabular}{|c|c|c|c|c|c|c|}
\hline \multirow{2}{*}{\multicolumn{2}{|c|}{ Number }} & \multicolumn{5}{|c|}{ Mass Fraction/\% } \\
\hline & & $\mathbf{O}$ & Al & Si & $\mathrm{Ca}$ & $\mathrm{Cr}$ \\
\hline \multirow{2}{*}{ a } & EDS-1 & 50.65 & 1.51 & 14.48 & 32.02 & 1.35 \\
\hline & EDS-2 & 53.90 & 1.30 & 11.63 & 32.07 & $\longrightarrow$ \\
\hline \multirow{2}{*}{$\mathrm{b}$} & EDS-1 & 53.51 & 1.29 & 14.28 & 29.57 & 1.34 \\
\hline & EDS-2 & 53.22 & 1.02 & 12.11 & 32.19 & $\longrightarrow$ \\
\hline \multirow{2}{*}{$\mathrm{C}$} & EDS-1 & 54.33 & 1.51 & 14.15 & 29.03 & 3.98 \\
\hline & EDS-2 & 53.98 & 1.77 & 14.02 & 29.13 & 4.10 \\
\hline
\end{tabular}

\section{Conclusions}

The present study attempted to investigate the effect of $\mathrm{Cr}$ on the mineral phase formation in cement clinkers. The major conclusion was that $\mathrm{Cr}$ affects the formation of $\mathrm{C}_{2} \mathrm{~S}$ and inhibits the generation of $\mathrm{C}_{3} \mathrm{~S}$. It does not, however, change the chemical environment of ${ }^{29} \mathrm{Si}$ in the clinker mineral phase. It is still an isolated silicon-oxygen tetrahedron, with the $\mathrm{Cr}-\mathrm{O}$ bond energy being weaker than that of Ca-O. The electronegativity of $\mathrm{Cr}^{3+}$ is also higher than that of $\mathrm{Ca}^{2+}$. Cr affects the orientation of the silicon tetrahedron and the coordination number of calcium, leading to defects in the crystal structure of the clinker mineral phase. $\mathrm{Cr}^{3+}$ replaces $\mathrm{Ca}^{2+}$ in the mineral phase lattice to form a new mineral phase, $\mathrm{Ca}_{3} \mathrm{Cr}_{2}\left(\mathrm{SiO}_{4}\right)_{3}$. Cr plays a stabilizing role in the calcination of clinker to promote the formation of $\beta-C_{2} S$. An increase in $\mathrm{Cr}$ content decreases the relative content of $\mathrm{C}_{3} \mathrm{~S}$ and increases that of $\mathrm{C}_{2} \mathrm{~S}$. Cr easily dissolves in $\mathrm{C}_{2} \mathrm{~S}$, and $\mathrm{C}_{3} \mathrm{~S}$ does not show the presence of $\mathrm{Cr}$.

Thus, this study provides novel experimental and theoretical evidence for the solidification mechanism of heavy metals in the cement clinker mineral phase. In addition, in the actual production of sludge collaborative disposal by cement kiln, the content of $\mathrm{Cr}$ element in sludge will increase with an increase in sludge content, which will decrease the content of $\mathrm{C}_{3} \mathrm{~S}$ in the clinker and increase the content of $\mathrm{C}_{2} \mathrm{~S}$. This degrades the quality and performance of the cement. Therefore, the pursuit for quantity should be avoided in sludge resource-based disposal, while the environmental risk from the Cr element is ignored, as well as the quality and performance risks of cement. 
Author Contributions: Conceptualization, H.F.; methodology, H.F. and M.L.; validation, M.L. and X.W.; investigation, M.L., X.W., and X.M.; writing-original draft preparation, M.L. and X.W.; writing-review and editing, H.F., J.X., X.M., and L.J. Funding acquisition, H.F. All authors have read and agreed to the published version of the manuscript.

Funding: This research was funded by the National Key R\&D Program of China (under Contract 2010ZX07319-002).

Acknowledgments: We would like to thank Editage (www.editage.cn) for English language editing.

Conflicts of Interest: The authors declare no conflicts of interest.

\section{References}

1. Huntzinger, D.N.; Eatmon, T.D. A life-cycle assessment of Portland cement manufacturing: Comparing the traditional process with alternative technologies. J. Clean. Prod. 2009, 17, 668-675. [CrossRef]

2. Finnveden, G.; Johansson, J.; Lind, P. Life cycle assessment of energy from solid waste—Part 1: General methodology and results. J. Clean. Prod. 2005, 13, 213-229. [CrossRef]

3. Yang, Q.; Lv, Z.F. Technical Analysis of Cooperative Disposal of Municipal Solid Waste by New Dry-process Cement Kiln. Chem. Eng. Equip. 2012, 195-197.

4. Xiang, C.Y. Curing Behavior of Heavy Metal Ions in Portland Cement Hydration Products. Ph.D. Thesis, Wuhan University of Technology, Wuhan, China, 2015.

5. Wang, M.G.; Wang, F.Z.; Shang, D.C.; Hu, S.G. Effect of CdO on the formation of tricalcium silicate and its solid solution effect. J. Mater. Sci. Eng. 2016, 34, 208-212.

6. Hu, S.G.; Nie, S.; Zhu, M.; Li, Y.Z.; Zhan, J.; Wang, F.Z. Performance Analysis of Derived Fuels for Cement Kilns Prepared by Municipal Solid Waste. J. Saf. Environ. 2014, 176-180.

7. Hou, X.L.; Ma, X.Q. Research Progress on Heavy Metal Pollution and Treatment of Municipal Refuse. Environ. Prot. Sci. 2006, 32, 30-31.

8. Xiang, C.Y.; He, Y.J.; Lu, L.N.; Wang, F.Z.; Li, Y.Q. Research on the performance of clinker kiln co-processing hazardous waste production clinker. Environ. Sci. Manag. 2013, 38, 81-86.

9. Katyal, N.K.; Ahluwalia, S.C.; Parkash, R. Effect of $\mathrm{Cr}_{2} \mathrm{O}_{3}$ on the formation of $\mathrm{C}_{3} \mathrm{~S}$ in 3CaO: $1 \mathrm{SiO}_{2}: \mathrm{xCr}_{2} \mathrm{O}_{3}$ system. Cem. Concr. Res. 2000, 30, 1361-1365. [CrossRef]

10. Enculescu, M. Influence of oxides of transitional elements on the properties of mineralogical components of clinker. In Proceedings of the 6th International Congress on the Chemistry of Cement, Moscow, Russia, 21-28 September 1974; Volume 19, pp. 351-355.

11. Xi, Y.Z. Curing mechanism of chromium in Portland cement. J. China Acad. Build. Mater. Sci. 1990, 2, 15-21.

12. Kolovos, K.; Tsivilis, S.; Kakali, G. SEM examination of clinkers containing foreign elements. Cem. Concr. Compos. 2005, 27, 163-170. [CrossRef]

13. Tong, D.Z.; Yu, Q.J.; Wang, S.B. XPS and ESR study of chromium ions in cement clinker. J. Chin. Ceram. Soc. 1988, 16, 370-376.

14. Barros, A.M.; Espinosa, D.C.R.; Tenório, J.A.S. Effect of $\mathrm{Cr}_{2} \mathrm{O}_{3}$ and $\mathrm{NiO}$ additions on the phase transformations at high temperature in Portland cement. Cem. Concr. Res. 2004, 34, 1795-1801. [CrossRef]

15. Fierens, P.; Verhaegen, J.P. Structure and reactivity of chromium doped tricalcium silicate. J. Am. Ceram. Soc. 1972, 55, 309-312. [CrossRef]

16. Stephan, D.; Mallmann, R.; Knöfel, D.; Härdtl, R. High intakes of Cr, Ni, and Zn in clinker: Part I. Influence on burning process and formation of phases. Cem. Concr. Res. 1999, 29, 1949-1957. [CrossRef]

17. Ste, D.; Maleki, H. Influence of $\mathrm{Cr}, \mathrm{Ni}$ and $\mathrm{Zn}$ on the properties of puree linker phases: Part I: $\mathrm{C}_{3} \mathrm{~S}$. Cem. Concr. Res. 1999, 29, 545-552.

18. Y, W.; L, W.; X, W.; Liu, Y.J.; Wei, L.Y. Solid solution behavior of $\mathrm{Cr}^{3+}$ ion in tricalcium silicate. Bull. Chin. Ceram. Soc. 2013, 32, 1253-1257.

19. Fang, Y.H. Application of solid high resolution nuclear magnetic resonance in cement chemistry research. J. Build. Mater. 2003, 54-60.

20. Feng, C.H.; Wang, X.J.; Li, D.X. Application progress of 29Si and 27Al solid nuclear magnetic resonance in cement-based materials. Nucl. Technol. 2014, 37, 48-53.

21. Xiao, J.M.; Fan, H.H.; Wu, Y.L.; Ma, Z. 29Si solid high resolution nuclear magnetic resonance analysis of sludge ash replacing clay calcined cement clinker. J. Mater. Sci. Eng. 2016, 34, 460-464. 
22. He, Y.J.; Hu, S.G. Application of 29Si solid nuclear magnetic resonance technology in cement chemistry research. J. Mater. Sci. Eng. 2007, 105, 148-157.

23. Trapote-Barreira, A.; Porcar, L.; Cama, J.; Soler, J.M.; Allen, A.J. Structural changes in C-S-H gel during dissolution: Small-angle neutron scattering and Si-NMR characterization. Cem. Concr. Res. 2015, 72, 76-89. [CrossRef]

24. Yang, N.R.; Yue, W.H. Manual of Atlas of Inorganic Nonmetallic Materials; Wuhan University of Technology Press: Wuhan, China, 2000; pp. 571-628.

25. Lu, P. Introduction to Cement Materials Science; Tongji University Press: Shanghai, China, 1991; pp. 18-55.

26. Liebau, F. Structural Chemistry of Silicate; China Construction Industry Press: Beijing, China, 1989.

27. Zhang, Q.T. Science Foundation of Inorganic Materials; East China University of Science and Technology Press: Shanghai, China, 2007.

(C) 2020 by the authors. Licensee MDPI, Basel, Switzerland. This article is an open access article distributed under the terms and conditions of the Creative Commons Attribution (CC BY) license (http://creativecommons.org/licenses/by/4.0/). 